\title{
DNA guidelines for further attenuation
}

$\mathrm{NIH}$ to consider new voluntary provisions

\section{Washington}

Two prominent members of the National Institutes of Health $(\mathrm{NIH})$ Recombinant DNA Advisory Committee (RAC) are suggesting a major transformation of the guidelines covering recombinant DNA research which would not only significantly reduce containment levels for a variety of experiments, but also convert the guidelines into a nonregulatory "code of standard practice". Dr Alan Campbell of Stanford University and Dr David Baltimore of the Massachusetts Institute of Technology claim that revoking the mandatory aspects of the guidelines is compatible with the experience gained since they were introduced five years ago.

The recommendation from Dr Campbell and Dr Baltimore will be discussed at next month's meeting of RAC. Also under consideration will be some less radical proposals suggested at a recent meeting of the chairpersons of local biosafety committees (Nature 288, 529; 1980), focusing primarily on reducing the paperwork involved in registering experiments conducted at the minimal P1 containment level, which is expected to receive the committee's support.

In a letter to Dr Donald Fredrickson, director of NIH, the two authors claim that since 1976, when the guidelines were introduced, neither experimental evidence nor theoretical arguments have been put forward to support the argument that recombinant DNA research poses any danger to human health. According to their proposal, the list of prohibited and exempt experiments would be retained, as would RAC. But all mechanisms which have been set up to enforce the guidelines as regulations - including, presumably, local institutional biosafety committees would no longer be required.

Dr Campbell and Dr Baltimore argue that singling out some classes of experiments as needing higher levels of physical containment has been made at the cost of discouraging variety and innovation and thereby limiting access to useful knowledge. In contrast, they say, "the benefit is likely to be zero".

If $\mathrm{NIH}$ agrees to move in this direction, it is likely to proceed cautiously. At the last RAC meeting in January, the committee approved by nine votes to eight, with three abstentions, a proposal from Dr Winston Brill of the University of Wisconsin that the guidelines be changed to permit recombinant DNA experiments using nonpathogenic prokaryotes and lower eukaryotes to be conducted at P1 containment.

However, in a notice published recently in the Federal Register, Dr Fredrickson says that in the light of the closeness of the vote, he is accepting in preference a compromise proposed by another committee member, Dr Susan Gottesman, which would allow the Office of Recombinant DNA Activities to lower containment levels for such experiments on a case-bycase basis, but without requiring RAC review.

One effect of the proposal of $\mathrm{Dr}$ Campbell and Dr Baltimore would be to throw into greater prominence suggested safety guidelines for microbiological and biomedical laboratories prepared by the Center for Disease Control (CDC) which, like NIH, is part of the Public Health Service. However CDC itself has become a recent focus of controversy, following its publication last autumn of an updated draft of what it calls a "national code of practice",

The document, which has been widely circulated to universities and other research laboratories, is divided into two principal sections; and it is the second

section which has generated the most detailed criticism. This contains proposals for treating several types of organisms in a way which many microbiologists feel would be overly restrictive - in particular using viruses such as SV40. As now written, the guidelines "would put most virologists out of business"' says Dr Harlyn Halvorson, chairman of the public and scientific affairs board of the American Society for Microbiology (ASM), which has been coordinating the views of several professional societies and is shortly to issue a detailed critique of the proposals.

CDC officials maintain that they are anxious to achieve a consensus on the guidelines, and plan a thorough revision in the light of the many comments that they receive. They also point out that the guidelines do not have the force of law outside public laboratories, and are intended more as a guide to local biosafety officers.

In reality, however, the CDC guidelines are likely to be widely adopted as a broad framework for dealing with potentially dangerous microorganisms, whether used in recombinant DNA experiments or not. In a letter to $C D C$ director Dr William H. Foege, ASM asks CDC to broaden the basis for discussions with the biomedical research community - something that

\section{Guidelines transgressor let off lightly}

\section{Washington}

Dr Ian Kennedy, discovered last year to have been cloning Semliki Forest virus and not Sindbis virus, has been let off with a caution. The review committee set up by the National Institutes of Health (NIH) to investigate charges that he had infringed regulations covering recombinant DNA research in his laboratory at the University of California in San Diego has decided that no further action can be taken against him. Dr Kennedy is no longer conducting research funded by NIH and has no grant application under review for NIH funding.

The panel has also, however, recommended that, in the light of what it claims was Dr Kennedy's failure to comply with the NIH guidelines covering recombinant DNA research, during the next two years "his use of such techniques may be made subject to such additional conditions as the awarding [NIH bureau, institute or division] may require"'.

The NIH review committee throws little light on whether, when Dr Kennedy performed experiments using Semliki Forest virus which were at the time proscribed by the NIH rules, he did so intentionally or merely as the result of cross-infection. "It would not be fruitful for NIH staff to engage in an extensive examination of Dr Kennedy's laboratory notebooks or to interview his co-workers in order to attempt a resolution of complicated and disputed chronology."
The committee, nevertheless, faults $\mathrm{Dr}$ Kennedy for not seeking prior approval for recombinant DNA experiments in mouse $\mathrm{L}$ cells, from which transformed RNA was analysed, and says that Dr Kennedy failed to act responsibly.

Commenting on the report, Dr Donald Fredrickson, director of NIH, said that he accepted the committee's recommendations, and has asked both NIH officials and the university chancellor, Dr Richard Atkinson, to take appropriate action.

The review committee's report comes two weeks after Dr Martin Cline agreed to step down permanently as head of the division of haematology and oncology at the University of California, Los Angeles, following the university's discovery that he had used recombinant DNA molecules in treating patients with thalassaemia without the consent of the university committee responsible for protecting human subjects during clinical experimentation.

A statement issued by the university said that although both the patients and their families were told of the benefits and risks of the experimental treatment - which was carried out on one patient in Italy and another in Israel - neither university nor hospital officials were informed. The university's chancellor, Charles E. Young, added, however, that no harm had come to the patients treated by Dr Cline, whom he hoped would remain at the university.

David Dickson 